Tropical Journal of Pharmaceutical Research February 2011; 10 (1): 55-60

(C) Pharmacotherapy Group, Faculty of Pharmacy, University of Benin,

Benin City, 300001 Nigeria.

All rights reserved.

Research Article

Available online at http://www.tjpr.org

\title{
Phytochemical Screening and In-vivo Antipyretic Activity of the Methanol Leaf-Extract of Bombax Malabaricum DC (Bombacaceae)
}

\section{Emdad Hossain ${ }^{1}$, Subhash C Mandal ${ }^{2}$ and JK Gupta ${ }^{2^{\star}}$}

${ }^{1}$ Pharmacy College, Azamgarh 276128, Uttar Pradesh, ${ }^{2}$ Department of Pharmaceutical Technology, Jadavpur University, Kolkata700 032, India

\begin{abstract}
Purpose: To investigate the antipyretic activity of the methanol extract of Bombax malabaricum leaves (MEBM) in rats.

Methods: Baker's yeast was used to induce fever in Wistar rats which were divided into four groups. The animal groups were thereafter administered MEBM (200 mg/kg), MEBM (400 mg/kg), paracetamol (reference standard, $150 \mathrm{mg} / \mathrm{kg}$ ) and $1 \%$ Tween 80 (control), respectively. The body temperature of the rats was measured rectally over a period of $8 \mathrm{~h}$. MEBM was also phytochemically screened for alkaloids, steroids, carbohydrates, tannins, fixed oils, proteins, triterpenoids, deoxy-sugar, flavonoid, cyanogenetic and coumarin glycosides.

Results: MEBM $(200 \mathrm{mg} / \mathrm{kg}$ and $400 \mathrm{mg} / \mathrm{kg})$ significantly reduced yeast-induced pyrexia $(p<0.05, p<$ 0.01 , respectively). Phytochemical tests showed the presence of steroids, carbohydrates, tannins, triterpenoids, deoxy-sugars, flavonoids and coumarin glycosides.

Conclusion: The methanol extract of Bombax malabaricum leaves possesses significant antipyretic activity.
\end{abstract}

Keywords: Antipyretic activity, Baker's yeast, Bombax malabaricum, Phytochemical screening

*Corresponding author: E-mail: jkgjupt@yahoo.co.in, hossainemdad@yahoo.com; Tel: +91-33-24053055;

Fax: +91-5462-243134 


\section{INTRODUCTION}

Fever is a common medical symptom associated primarily with elevation of body temperature and is often accompanied by certain sickness-related behavioural features such as depression, sleepiness, lethargy, hyperalgesia, anorexia, etc. A number of disease conditions such as infections, skin inflammation, immunological disorders, tissue destruction, cancer, metabolic disorders, and reaction to incompatible blood products, usually accompany fever [1]. Mechanistically, the hypothalamus of the brain controls the heat effector mechanism via the autonomic nervous system, either by increase of heat production (through increased muscle tone or shivering) or prevention of heat loss by vasoconstriction [1]. There is controversy regarding the usefulness of fever; however, high temperature is always considered a medical emergency due to its serious side effects such as intracranial haemorrhage, sepsis, Kawasaki syndrome, thyroid storm, and serotonin syndrome [1].

The search for an ideal antipyretic drug is a never-ending challenge. Paracetamol and other popular synthetic antipyretic drugs have several side effects [2]. Therefore, it is worth searching for herbal materials that are equally efficacious but less toxic and comparatively free from side effects, as substitutes for synthetic drugs such as paracetamol.

The plant, Bombax malabaricum DC. (silk cotton tree) \{Synonym: Bombax ceiba L.; Salmalia malabaricum Schott \& Endl.\}, belongs to the family Bombacaceae. It has been shown to be important in traditional medicine [3]. It is a lofty deciduous tree of up to 40 meters in height; its young stems and branches are covered with stout, hard prickles; its leaves are large, spreading, glabrous and digitate; leaflets are 5-7, lanceolate and $10-20 \mathrm{~cm}$ long; its flowers numerous, large, fleshy, bright crimson, yellow or orange, clustered at the end of the branches while its capsules are oblong-ovoid, containing many seeds with long, dense silky hairs. It is found in the tropical and subtropical regions of the world. The plant is economically important as a source of cotton and timber, including its use for the production of match-sticks. [3].

The leaves are used traditionally in inflammation and cutaneous trouble [3,4]. Its leaf extract exhibits significant antifungal activities against ringworm infection while the bark gum contains catechutannic acid [5]. Dar et al [6] isolated antioxidant and analgesic mangiferin from the leaves of the plant. The root contains bombamalones A-D, bombamaloside, isohemigossypol- 1-methyl ester, 5,2-O-methylisohemigossylic acid lactone, 6-bombaxquinone $\mathrm{B}$ and lacinilene $\mathrm{C}$ [7] while the petal contains orange-red anthocyanin pelargonidin-5- $\beta$-D-glucopyranoside and cyanidine-7-methyl ether-3 $\beta$ glucopyranoside. The root-bark contains lupeol, $\beta$-sitosterol, 8-formyl-7-hydroxy-5isopropyl-2-methoxy-3-methyl-1,4-napthaquinone, isohemiglogossyol-1-methyl ether and 7-hydroxycadalene [3]. Lupeol, $\beta$-sitosterol and $\beta$-sitosterol-D-glucoside have been isolated from its stem bark while lupeol, $\beta$ sitosterol and two naphthaqinones were obtained from the root bark of the plant [8].

To the best of our knowledge, there is no report on the antipyretic activity of the methanol extract of the leaves of Bombax malabaricum. The purpose of the present work, therefore, was to investigate the methanol extract of Bombax malabaricum leaves (MEBM) for its antipyretic activity. Phytochemical screening of the extract was also carried out.

\section{EXPERIMENTAL}

\section{Chemicals and reagents}

Methanol was obtained from $\mathrm{CDH}$, India. Paracetamol was obtained from GlaxoSmithKline, India. Other chemicals and reagents used were of analytical grade. 


\section{Plant material}

The fresh leaves of Bombax malabaricum were collected from the city of Azamgarh, Uttar Pradesh, India during the month of May 2008 and were identified by $\mathrm{Dr} \mathrm{HJ}$ Chowdhery, a taxonomist and Joint Director, Central National Herbarium $(\mathrm{CNH})$, Botanical Survey of India, Howrah, India The voucher specimen (no. CNH/1-I(314)/2009-Tech II/356/346) was deposited in the herbarium of $\mathrm{CNH}$, Botanical Survey of India, Howrah, India for future reference. The leaves were dried under the shade, powdered and then stored in an air-tight container prior to use.

\section{Preparation of extract}

The powdered leaves were extracted in a Soxhlet apparatus using methanol as solvent. The solvent was removed from the extract in a rotary vacuum evaporator and the extract subsequently dried in a vacuum oven at 45 ${ }^{0} \mathrm{C}$ to obtain a solid mass of the crude extract which was kept in a desiccator prior to use in the animal studies.

\section{Preliminary phytochemical screening}

Preliminary phytochemical screening for alkaloids, steroids, carbohydrates, tannins, fixed oils, proteins, triterpenoids, deoxysugar, flavonoid, cyanogenetic and coumarin glycosides carried out on the extract according to the procedures of Khandelwal [9]. Test for alkaloids carried out using Mayer's, Dragendorff's, Wagner's and Hager's reagents. Presence of steroid was confirmed with Libermann-Burchard, Salkowski, and Libermann's reactions. Test for carbohydrate was undertaken using Fehling's, Benedict's, Molish's, Tollen's and iodine tests. Keller-Killiani test was done to confirm the presence of deoxy-sugar. Noller's reagent was used to test for triterpenoids. Shinoda and Wolform tests were used for the identification of flavonoids. The presence of tannins was determined by reaction with $5 \%$ ferric chloride, acetic acid, lead acetate, gelatin, dilute potassium permanganate, potassium dichromate solution, bromine water and dilute nitric acid. For cyanogenetic glycoside, Guignard reaction was used whereby a filter paper strip was soaked in 10 $\%$ picric acid and $10 \%$ sodium carbonate, respectively. It was kept in the slit of a cork over the moistened extract in a conical flask. Brick red or maroon colour confirms the positive test for cyanogenetic glycosides. Blue or green fluorescence indicates a positive test for coumarin glycosides when the alcoholic extract is rendered alkaline. The extract was tested for protein using biuret and ninhydrin tests and also by reacting with Million's reagent. The presence of fixed oils by means of spot and saponification tests.

\section{Test animals}

Wister rats of either sex and weighing 120 $130 \mathrm{~g}$ were used for the antipyretic test. The animals were kept under controlled conditions (temperature, $25 \pm 2{ }^{0} \mathrm{C}$; light/dark cycle, 12/12 h) and fed with standard pellet diet and water ad libitum. The study received prior approval from the Institutional Animal Ethical Committee, Pharmacy College, Azamgarh, India (approval reference no. 937/c/06/CPCSEA). Animal handling was followed the guidelines of the Committee for the Purpose of Control and Supervision of Experiments on Animals (CPCSEA) [10].

\section{Preparation of extract for animal studies}

The crude extract (MEBM, $600 \mathrm{mg}$ ) was suspended in $1 \%$ aqueous Tween 80 (15 $\mathrm{ml})$. Control treatment was with $1 \%$ Tween 80 while the reference standard was paracetamol $(250 \mathrm{mg})$ suspended in $1 \%$ Tween 80 (17 ml).

\section{Induction of pyrexia}

Antipyretic activity was measured by slightly modifying the method described by Dewan et al [11]. The rats were divided into four groups of six animals each. Rectal temperature was measured by introducing a $3 \mathrm{~cm}$ digital thermometer (Model MT-101, N \& B Medical, 
Delhi) coated with glycerin (lubricant) into the rectum. Pyrexia $(10 \mathrm{ml} / \mathrm{kg})$ was induced by intra-subcutaneous injection of $20 \%$ Baker's yeast suspended in $0.9 \%$ saline.

\section{Drug administration}

Four hours after yeast injection, the animal groups received orally MEBM $(400 \mathrm{mg} / \mathrm{kg}$ or $200 \mathrm{mg} / \mathrm{kg}$ ), paracetamol (reference standard (150 mg/kg) and $1 \%$ Tween 80 (control), respectively. Body temperature was measured via the rectum hourly from 0 to $8 \mathrm{~h}$ [11].

\section{Statistical analysis}

All the results are expressed as the mean \pm S.E.M. The data were analyzed for statistical significance by one-way analysis of variance (ANOVA) followed by Tukey test using computerized GraphPad Prism, version 4.03 software (Graph Pad Software Inc). Values of $p<0.05$ were considered statistically signifycant.

\section{RESULTS}

\section{Phytochemical screening}

The outcome of the preliminary phytochemical screening of the extract showed the presence of steroids, carbohydrates, tannins, triterpenoids, deoxysugar, flavonoids and coumarin glycosides.

\section{Antipyretic activity}

Administration of Baker's yeast produced an increase in the body temperature of the rats from normal $\left(37.66 \pm 0.02{ }^{\circ} \mathrm{C}\right)$ to $38.69 \pm 0.03$ ${ }^{0} \mathrm{C}$ within four hours of yeast injection. Fig 1 shows that maximum temperature was attained in the control group at $1 \mathrm{~h}$ (i.e., $5 \mathrm{~h}$ after yeast administration) with a value of $39.2 \pm 0.04{ }^{\circ} \mathrm{C}$. MEBM $(200 \mathrm{mg} / \mathrm{kg}, 400$ $\mathrm{mg} / \mathrm{kg}$ ) and paracetamol reduced the body temperature to $38.17 \pm 0.05{ }^{\circ} \mathrm{C}, 37.97 \pm 0.05$ ${ }^{0} \mathrm{C}$ and $37.91 \pm 0.05{ }^{\circ} \mathrm{C}$, respectively after 6 h. MEBM's antipyretic activity at doses of 200 $\mathrm{mg} / \mathrm{kg}(p<0.05)$ and $400 \mathrm{mg} / \mathrm{kg}(p<0.01)$ was higher than that of control. However, the standard drug, paracetamol $150 \mathrm{mg} / \mathrm{kg}$ demonstrated the excellent antipyretic activity $(p<0.001)$ compared with that of control. After $8 \mathrm{~h}$, body temperature in the MEBMtreated groups $(200$ and $400 \mathrm{mg} / \mathrm{kg})$ remained essentially unchanged at $38.21 \pm$ 0.07 and $37.99 \pm 0.04{ }^{\circ} \mathrm{C}$, respectively.

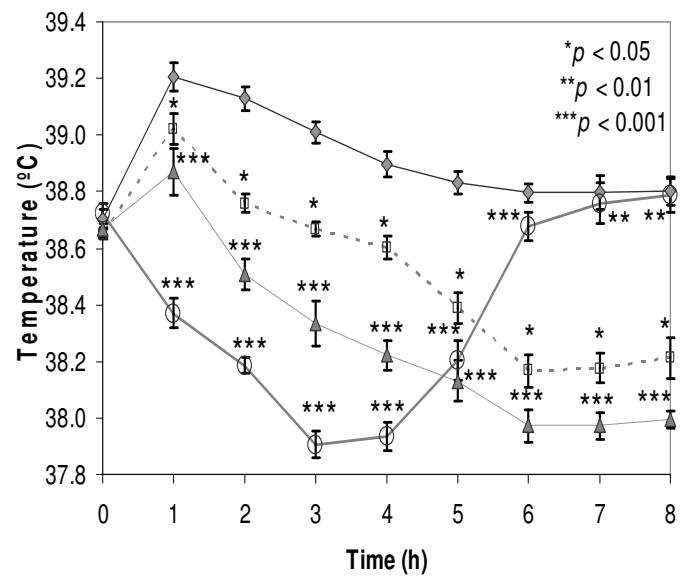

Figure 1: Antipyretic effect of MEBM on Baker's yeast-induced pyrexia in rats $(\bullet=$ control; $\square=$ MEBM $200 \mathrm{mg} / \mathrm{kg} ; \quad \boldsymbol{\Delta}=$ MEBM $400 \mathrm{mg} / \mathrm{kg} ; \quad \mathrm{O}=$ paracetamol $150 \mathrm{mg} / \mathrm{kg}$ )

\section{DISCUSSION}

The present study showed that the methanol extract of Bombax malabaricum (MEBM) possessed significant antipyretic activity in Baker's yeast-induced pyrexia. The standard (paracetamol) achieved maximum antipyretic activity in $3 \mathrm{~h}$; its activity decreased subsequently probably due to metabolism and excretion of the drug. On the other hand, maximum antipyretic activity for MEBM occurred at $6 \mathrm{~h}$, indicating slow but steady absorption of the drug from the GIT; this may have been responsible for the prolonged action of the extract. Subsequently, up to the $8^{\text {th }}$ hour, its activity remained largely unchanged. The antipyretic activity of the extract was dose-dependent with the higher dose producing greater activity. 
The hypothalamus regulates body temperature with a delicate balance between heat production and heat loss through the set-point control. Infection, tissue damage, inflammation, graft rejection, malignancy and several other ill-health conditions may elevate the set point to induce fever [12]. When the set point is raised, enhancement of the body temperature takes place through active generation and retention of heat. Vasoconstriction also helps to reduce heat loss through skin. In this way, the body matches the brain blood temperature with the new set point made by the hypothalamus [1]. Biochemically, during fever, enhanced formation of cytokines such as interleukins (IL-1 $\alpha$, IL-1 $\beta$, IL-6 and IL-6), interferon ( $\alpha, \beta)$, tumour necrosis factor alpha (TNF- $\alpha$ ) takes place under such physiological conditions [12]. These cytokine factors migrate to circumventricular organs of the brain and bind with endothelial receptors on vessel walls or interact with local microglial cells. After binding, it activates the arachidonic acid pathway which enhances the synthesis of prostaglandin $E_{2} \quad\left(P_{G} E_{2}\right)$. The pathway consists of the enzymes phospholipase A2, cyclo-oxygenase-2 (COX-2) and prostaglandin $E_{2}$ synthase, which are responsible for the synthesis and release of $P G E_{2}$. $P G E_{2}$ is the final mediator for febrile response. The set point temperature of the body remains elevated until $\mathrm{PGE}_{2}$ is present in the hypothalamus [1]. Again, $\mathrm{PGE}_{2}$ triggers the hypothalamus for more formation of heat by minimizing heat loss through cyclic adenosine mono-phosphate (cAMP) pathways [12]. It has been established that yeast induces pathogenic fever in rat by enhancing the production of prostaglandins, mainly $P G E_{2}$, which elevates the set point of the thermoregulatory centre in hypothalamus [13].

Paracetamol possesses potent antipyretic and analgesic activities with minimal antiinflammatory activity. It may selectively inhibit specific COX isoform in the CNS to inhibit prostaglandin synthesis to achieve its antipyretic effect [14] but does not influence body temperature when it is elevated by factors such as exercise or increase in ambient temperature [12]. Certain phytochemical compounds such as steroids, carbohydrates, tannins, triterpenoids, flavonoid and coumarin glycosides were found to be present in the extract during phytochemical screening. The antipyretic potentials of steroids, tannins, triterpenoids, flavonoid and coumarin glycosides have been reported in various studies [15-18]. Therefore, the antipyretic activity of MEBM may be due to its contents of steroids, tannins, triterpenoids, flavonoid and coumarin glycosides.

Furthermore, indirect evidence seems to support the influence of MEBM on the biosynthesis of prostaglandin $\left(\mathrm{PGE}_{2}\right)$ which is a regulator of body temperature; this may also partly account for its antipyretic activity in yeast-induced pyrexia model $[1,11]$.

\section{CONCLUSION}

The results obtained demonstrate the significant antipyretic activity of the methanol extract of Bombax malabaricum leaves. Inhibition of the synthesis and/or release of inflammatory mediators may be its main mechanism(s) of action. These results also suggest that the presence of certain bioactive molecules may partly be responsible for the reported antipyretic activity of MEBM, the isolation of which could help to obtain improved antipyretic drugs with specific mechanism of action. Further experimentation is under way in our laboratory to isolate the active molecules from MEBM and to establish the exact mechanism of action of the extract.

\section{ACKNOWLEDGMENT}

We are thankful to Dr. Anup Maiti, Pharmacy College, Azamgarh, India for his help in determining the antipyretic activity of the test extracts. 


\section{REFERENCES}

1. Fever [updated 2010 June 13; cited 2010 June 18]. Available from: http://en.wikipedia.org/ wiki/fever.

2. Bennett PN, Brown MJ. Clinical Pharmacology. Indian Reprint (2005). New Delhi: Churchill Livingstone, 2003; $p 287$

3. Wealth of India. Volume II. New Delhi: Publication and Information Directorate, CSIR, 1988; $p$ 177.

4. Chatterjee A, Pakrashi SP. The Treatise on Indian Medicinal Plants. Volume 3. New Delhi: Publication and Information Directorate, CSIR, 1994; $p 10$.

5. Wealth of India. Volume I, First supplement, New Delhi: Publication and Information Directorate, CSIR, 2000; $p 145$.

6. Dar A, Faizi S, Naqvi S, Roome T, Rehman SZ, Ali $M$, Firdous $S$, Moin ST. Analgesic and antioxidant activity of mangiferin and its derivatives: the structure activity relationship. Biol Pharm Bull 2005; 28(4): 596-600.

7. Zhang $X$, Zhu $H$, Zhang $S$, $Y u$, Xuan $L$. Sesquiterpenoids from Bombax malabaricum. J Nat Prod 2007; 70: 1526-1528.

8. Sheshadri V, Batta AK, Rangaswami S. Phenolic components of Bombax malabaricum. Curr Sci 1971; 23:630.

9. Khandelwal KR. Practical Pharmacognosy. Pune: Nirali Prakashan; 2006, p.149.

10. CPCSEA guidelines for laboratory animal facilities. Chennai: Committee for the purpose of control and supervision of experiments on animals (CPCSEA); $p 3$.

11. Dewan S, Suresh K, Vijay LK. Antipyretic Effect of Latex of Calotropis procera. Ind J Pharmacol 2000; 32(3): 252.

12. Goodman LS, Gilman AG. The Pharmacological Basis of Therapeutics. New York: The McGraw Hill Companies Inc, 2001; 0690.

13. Rititid $W$, Ruangsang $P$, Reanmongkol $W$, Wongnawa M. Studies of the anti-inflammatory and antipyretic activities of the methanolic extract of Piper sarmentosum Roxb. Leaves in rats. Songklanakarin J Sci Tech 2007; 29(6): 1519-1526.

14. Rang HP, Dale MM, Ritter JM. Pharmacology. London: Harcourt Publisher Limited, 2001; $p$ 232.

15. Kim HP, Son $K H$, Chang HW, Kang SS. Antiinflammatory plant flavonoids and cellular action mechanisms. J Pharmacol Sci 2004; 96: 229-245.

16. Niazi J, Gupta V, Chakarborty P, Kumar P. Antiinflammatory and antipyretic activity of Aleuritis moluccana leaves. Asian J Pharm Clin Res 2010; 3(1):35-37.

17. Tiwari V, Tiwari A, Madhavan V. Preliminary phytochemical analysis, HPTLC studies and antipyretic activity of alcohol and aqueous extract of Helicteres isora L. Root. Int $J$ Pharmacy Pharm Sci 2010; 2(2): 74-79.

18. Niazi J, Singh $P$, Bansal $Y$, Goel RK. Antiinflammatory, analgesic and antipyretic activity of aqueous extract of fresh leaves of Coccinia indica. Inflammopharmacol 2009; 17: 239-244. 